International Journal of Production Research, Volume 56, ssue 6, 2018, pp. 2133-2149

DOI:10.1080/00207543.2017.1332791

\title{
Remote monitoring technology and servitised strategies - factors characterising the organisational application
}

\author{
Tonci Grubic ${ }^{\mathrm{a} *}$ and Ian Jennions ${ }^{\mathrm{b}}$ \\ ${ }^{a}$ Business School, Liverpool Hope University, Liverpool, UK; ${ }^{b} I V H M$ Centre, Cranfield University, Cranfield, UK
}

(Received 26 July 2016; accepted 10 May 2017)

\begin{abstract}
This paper introduces factors that characterise the organisational application of remote monitoring technology (RMT) for servitised strategies. Factors were developed through in-depth case studies of four manufacturers operating in aerospace, industrial equipment, marine and transportation sector. They suggest a very complex, multi-levelled, multifaceted and circular relationship between RMT and servitisation. When unfolding this relationship we need to consider: the value proposition, nature of the product and its hierarchical position in the customer's business, RMT functionality, type and amount of data required, and a number of other factors that either complement or constrain the use of RMT. By providing the necessary lenses, the proposed factors can help in exploring this complexity. One such exploration questions our understanding of outcome-based contracting.
\end{abstract}

Keywords: product service systems; technology management; remote monitoring technology; servitisation; strategies; factors

\section{Introduction}

Servitisation centres on selling a solution to support a customer (Mathieu 2001) where emphasis is placed on value-in-use rather than exchange value (Vargo and Lusch 2004). Examples are integrated combinations of products and services where the emphasis shifts from selling a product to selling the 'use' or performance of a product (Baines et al. 2009). A growing number of established manufacturers have adopted servitisation with Rolls-Royce being one of the most commented examples. Here, airline customers can choose between a traditional time and materials contract and one centred on paying for use, 'power-by-the-hour' (Ostrom et al. 2015). Engine health management technology is recognised as central in this. It tracks the health of thousands of engines operating worldwide via onboard sensors that collect and transmit health data over satellites thus enabling the service provision (Waters 2009). Through such technologies manufacturers can access their equipment over long distances thus increase the effectiveness of services provided (Schumann, Wünderlich, and Wangenheim 2012). Paluch (2014) argues that remote services are supposed to become the fastest growing IT-enabled services in the next few years.

While servitisation has attracted a lot of interest from academia, for example, see recent literature reviews by Lightfoot, Baines, and Smart (2013) and Luoto, Brax, and Kohtamäki (2017), this community has very much neglected the role of technologies such as engine health management in servitisation. This paper is an attempt to narrow the gap in understanding. It addresses the following research question: what factors characterise the organisational application of Remote Monitoring Technology (RMT) in the context of servitised strategies? We propose that the organisational application can be characterised with at least six factors. They encompass the key choices a decision-maker is facing and can be used, positively or negatively, in forming a business solution. The study may be considered a step towards developing a better understanding about organisational capabilities necessary for exploiting RMT in the context of servitised strategies.

The rest of the paper is structured as follows. Next section presents a review of literature at the intersection between RMT and servitisation with specific emphasis on organisational implications. The following section introduces the research method. Following this, key findings are presented in the form of six factors found to shape the application of RMT in the context of servitised strategies. Before the conclusion, contributions of this study will be discussed. 


\section{Servitisation and RMT - literature review}

\section{$\boldsymbol{R M T}$ - definition and role in servitisation}

The case of US machine tool manufacturer Kearney and Trecker shows that RMT is decades old (Küssel et al. 2000). However, the research in this domain is predominately technology oriented and lacking the wider assessment of the technology's value creation potential in a business context. It focuses mainly on tools and techniques related to technical development and implementation (e.g. see Isermann and Ballé 1997; Leonhardt and Ayoubi 1997; Jardine, Lin, and Banjevic 2006; Kothamasu, Huang, and VerDuin 2006; Heng et al. 2009). This approach omits the concepts of value and risk, which are essential for servitisation. A servitised value proposition deals with a transfer of risks from the customer to the supplier, the key risks being non-availability of the product and its suboptimal performance.

Companies are now looking for ways to mitigate these risks and application of technologies such as engine health management is one example. Other examples include: RMT (Davies 2004; Grubic 2014), remote diagnostics (Brax and Jonsson 2009), remote services (Paluch 2014), smart products (Porter and Heppelmann 2014), smart technology (Ostrom et al. 2015), smart services (Wuenderlich et al. 2015), digitised products (Novales, Mocker, and Simonovich 2016) and digitalisation (Lenka, Parida, and Wincent 2017). We follow Davies (2004) and Grubic (2014) by using RMT. Irrespective of the name the key principle behind is the same. It involves real-time monitoring and collection of data on performance and usage of a product in the field to determine its current and predicted condition and health.

Figure 1 illustrates this principle. In real time, the technology senses and acquires data (e.g. pressures, temperatures, vibrations) about the health, performance and usage of a gas turbine (for example), which, upon being transferred and analysed on the ground (using diagnostic and prognostic algorithms), is turned into information about current and predicted health of the product that can be acted upon in a manner that optimises maintenance and reduces the abovementioned risks of servitisation.

\section{RMT - an important but ignored enabler of servitisation}

RMT is widely recognised as one of the key enablers of servitisation. Oliva and Kallenberg (2003) argue that RMT does not add value to customers per se; the real value of RMT becomes obvious only when it is used in the context of higher product availability value propositions. Smith (2013) found that technology, particularly engine health management, was a powerful enabling factor facilitating the move of Rolls Royce, and of the other two main aero engine manufacturers (GE, and Pratt and Whitney), to servitisation. Evidence for this is also found in Wuenderlich et al. (2015) who say (444): 'For example, Rolls-Royce uses remote sensors to monitor real-time engine data in flight as a key part of its service offering, where it sells use (power-by-the-hour) rather than selling aero engines'.

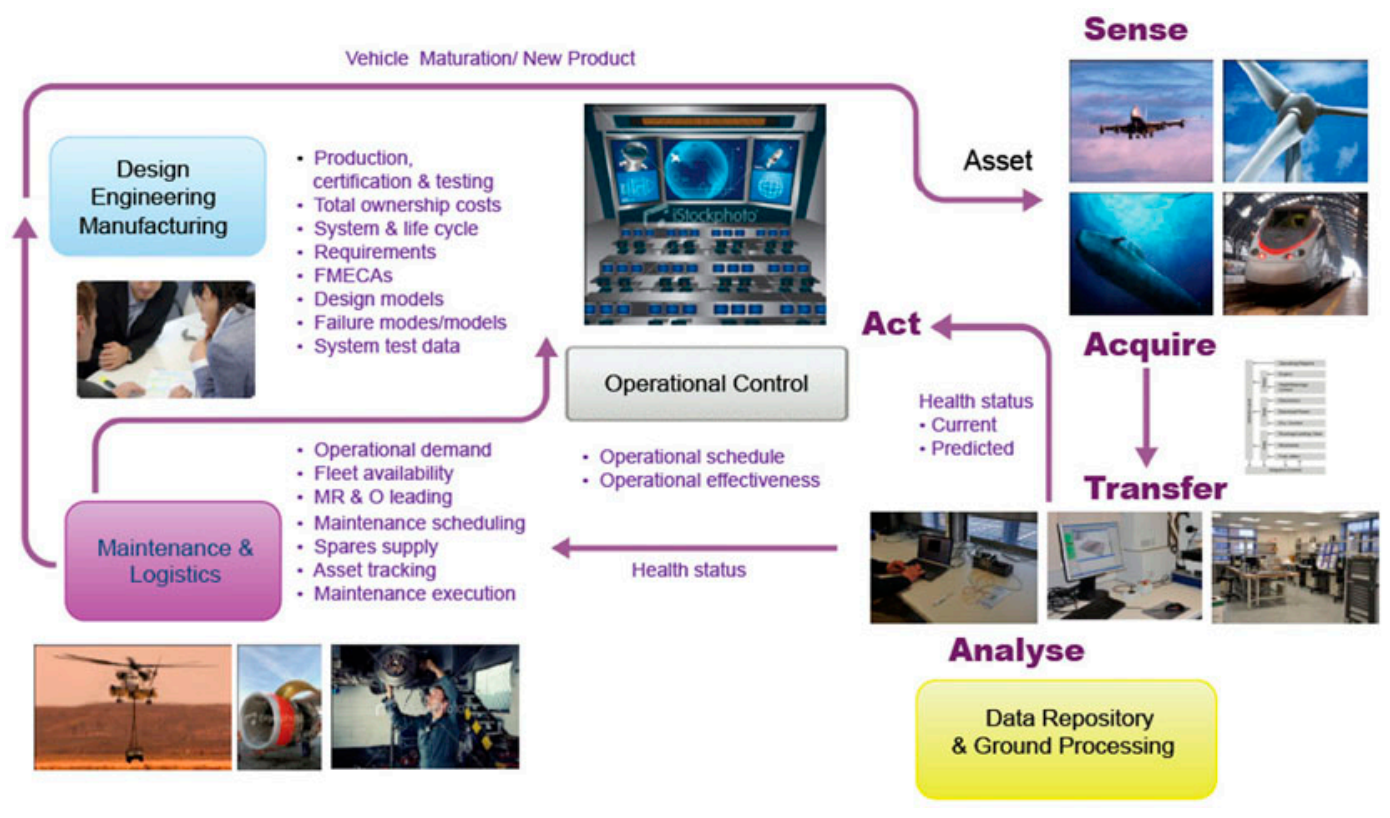

Figure 1. Remote monitoring technology (right hand side of figure) as part of an overall service delivery (Jennions 2011). 
RMT is not only important for Rolls Royce, it is found elsewhere. From their study of advanced services, Baines and Lightfoot (2014) found it essential that manufacturers deploy remote monitoring of a product's location, condition and use. Similar observations are made by Ulaga and Reinartz (2011), Raddats, Burton, and Ashman (2015) and Story et al. (2017). Based on interviews with 22 manufacturing executives, Ulaga and Reinartz (2011) identified the key resources and capabilities required to deliver successful servitised offerings. Data on installed base product usage provided by RMT were identified as the key strategic resource, and the capacity to process and interpret this data as the key organisational capability. These findings are corroborated by Raddats, Burton, and Ashman (2015) and Story et al. (2017). The former surveyed UK manufacturing to identify key capabilities for successful service development and delivery. Two were identified: service orientation of a leadership and service personnel, and service-based IT tools, e.g. equipment monitoring. Story et al. (2017) propose that capability to deploy telemetry or telematics is crucial business activity for the implementation of advanced services, e.g. availability contracting, and risk and revenue sharing.

The overwhelming evidence about the importance of RMT for servitisation is in stark contrast with the level of interest in this topic. Kowalkowski, Kindström, and Gebauer (2013) argue that despite the importance of technology for servitisation, this topic has been neglected by the servitisation research. From a systematic review of the literature, Lightfoot, Baines, and Smart (2013) identified limited awareness about the use of technologies, such as engine health management, which enable servitisation. Smith (2013) observed that in the literature the move to servitisation is normally attributed to economic, demand and competitive factors, and almost no credit is given to the role of technology in this move. Paluch (2014) reports a gap in the literature on remote services saying that very little, mainly descriptive, research exists that addresses RMT from a management viewpoint. The recent reviews of literature in this area (Grubic 2014; Novales, Mocker, and Simonovich 2016) confirm the above. They show that the relationship between RMT and servitisation is an under researched topic with only a handful of relevant research contributions. This is demonstrated in the case of factors characterising the organisational application of RMT.

\section{RMT and servitisation: factors characterising the organisational application}

The state of knowledge on this topic can be characterised as fragmented and very limited, which is not new and has been recognised earlier. Grubic (2014) conducted an extensive literature review on RMT and servitisation and identified limited empirical investigation of industrial applications of RMT and its role in servitised strategies. Similarly Wuenderlich et al. (2015) builds on discussions of the 2014 workshop on perspectives on technology in service organised by the international network of service researchers, and identifies a number of research gaps. Among others, they identified limited understanding of determinants that contribute to increasing a company's capability to provide RMT-enabled services. This nicely summarises the state of research about factors characterising the organisational application of RMT. However, though limited in nature, there are a growing number of studies in this area. Findings from their analysis can be grouped under three broad categories of: (1) challenges, (2) nature of product and (3) RMT functionality.

Evidence on challenges falls under two topics: limitations of RMT, and changing mindset. In relation to RMT limitations, problems with manual handling of data between various information systems and lack of standardisation to support sharing and integration of sensor data have been identified (Brax and Jonsson 2009). Kuschel (2009) found that companies struggle to integrate data from RMT into their information systems. Mahlamäki et al. (2016) found that companies are not able to form a comprehensive view of the installed base due to restricted interaction between various information systems (e.g. product development or service operations). The changing mindset challenge relates to a shifting emphasis from products to services. Allmendinger and Lombreglia (2005) argue that realising benefits from RMT and translating these into customer value propositions is not entirely a technical challenge. A bigger challenge is to get the senior management to adopt a service perspective on business. This resonates with Grubic et al. (2011) who surveyed the whole UK manufacturing sector to establish the extent of use of RMT in service provision. They found that realising the benefits of RMT requires tackling a number of challenges, most of which fall into the business and cultural domains rather than to advances in RMT.

This study also offers some insights about the importance of product. Namely, a correlation is identified between the nature of the product and the capacity to develop and deploy RMT. Thus, RMT is typically deployed onto a mechanical or electro-mechanical product with a long life cycle and a high degree of complexity (Grubic et al. 2011). This is supported by Lerch and Gotsch (2015) who found that complexity of the core product and of services offered influences the degree of RMT employed. The more complex a product and the more ambitious the supporting service, the more support is needed from the RMT. This brings us to the third factor, i.e. RMT functionality.

From a review of the literature on the use of RMT-enabled products in service provision, Novales, Mocker, and Simonovich (2016) have identified five conceptual elements that characterise this phenomenon. These are: (1) hybridity or the combination of digital and physical product components, (2) smartness or the product's context-awareness ability, 
(3) connectivity or the product's ability to exchange the acquired data via networks, (4) servitisation and (5) the digitised product ecosystem or combining complementary products and services to enhance the overall value offering. Of specific importance here is smartness. The importance of this element has also been recognised by Grubic et al. (2011) and Porter and Heppelmann (2014). The former have found that RMT provides a broad spectrum of functionalities, such as detection, diagnostic or decision support. Porter and Heppelmann (2014) identified a number of functionalities which they grouped into four areas: (1) monitoring, (2) control, (3) optimisation and (4) autonomy. The problem is that different authors consider different aspects when discussing this factor, hence no broad agreement exists (Novales, Mocker, and Simonovich 2016).

The literature on the phenomenon of organisational implications of RMT is fragmented and diffused across separate sources. No research can be found that looks specifically into this matter or provides advice on how to integrate such diverse information. This is in agreement with Novales, Mocker, and Simonovich (2016). They found no research that considers differences of the various conceptual elements and the implications of combining them. When these remarks are considered together with the two research gaps identified earlier (Grubic 2014; Wuenderlich et al. 2015) it becomes evident that our understanding of organisational implications of RMT is very limited. For these reasons, this study focuses on the following research question: what factors characterise the organisational application of RMT in the context of servitised strategies?

\section{Research method}

Case-study research was employed because the objectives were to provide description and explanation of an emerging and little understood phenomenon. Yin (2003) defines a case-study research as an empirical inquiry that investigates some contemporary phenomenon in a real-life setting where the boundaries of the phenomenon of interest and environment are not clear. The key idea is to use cases as the basis to develop theory inductively (Eisenhardt and Graebner 2007). Benefits of using case-study research include: observation of actual practices (Meredith 1998), greater understanding of the nature and complexity of research phenomenon (Ellram 1996; Meredith 1998; Yin 2003) and provision of much needed exploratory depth (Meredith 1998), especially in areas where existing theories are either inadequate or missing (Eisenhardt 1989).

Steps involved when designing case-study research include (Yin 2003): (1) selection of case studies, (2) designing a data collection protocol and (3) analysis and synthesis. By adopting the multiple case-study strategy, we aimed to increase the external validity, recognised as a significant issue in case-study research (Yin 2003). Theory built from multiple cases is considered more robust and generalisable than that from single-case research (Eisenhardt and Graebner 2007). When selecting the case studies the following criteria were used: (1) the organisation is a product manufacturer, (2) the organisation has service-oriented value propositions and (3) the organisation is using RMT to support those. Due to resource and time constraints, it was decided to conduct four descriptive case studies. Having used RMT for a number of years, the case companies were recognised as exemplars. Their brief overview together with other contextual information is shown in Table 1. Three case studies are based in the UK. The fourth (Marine Co.) is operating from Norway, serving the oil and gas industry, and Finland, serving the cruise and ferry industry. Transportation Co. serves only UK customers while the other three companies have customers worldwide. All four case studies are established and globally recognised companies.

A data collection protocol is an instrument that ought to ensure the collection of data necessary to address the research question. It needs to identify the subjects to be interviewed, the questions to be asked and specify any other secondary data required. The main source of evidence is qualitative data gathered via semi-structured interviews. These were arranged in three sets of questions covering three levels: company, operational and service.

The company-level questionnaire was used with persons who are either a 'business pull' for RMT or are responsible for its business development. The operational-level questionnaire was used with persons engaged with key customers or customer segments. It aimed to uncover details about specific product and service combinations offered and the role and contribution of RMT in those offers. The service-level questionnaire was used with maintainers, technicians and service engineers who deliver RMT-enabled services. The goal was to gain an understanding about their daily activities in using RMT in service delivery. To remain sensitive to any emerging issues, the questionnaires were designed with overlaps among them. For example, each set of questions covered the same four broad areas of: general company, product-service offerings, RMT and other necessary capabilities. However, the depth and the breadth depended on the responsibilities of the person being interviewed.

In total, 27 interviews were conducted (Table 1) covering a wide range of job roles (e.g. head of RMT, service operations engineer, sales manager, general manager, business development manager, operations room engineer, predictive maintenance specialist). Each interview was recorded and transcribed verbatim. The interview data were enriched with 
International Journal of Production Research

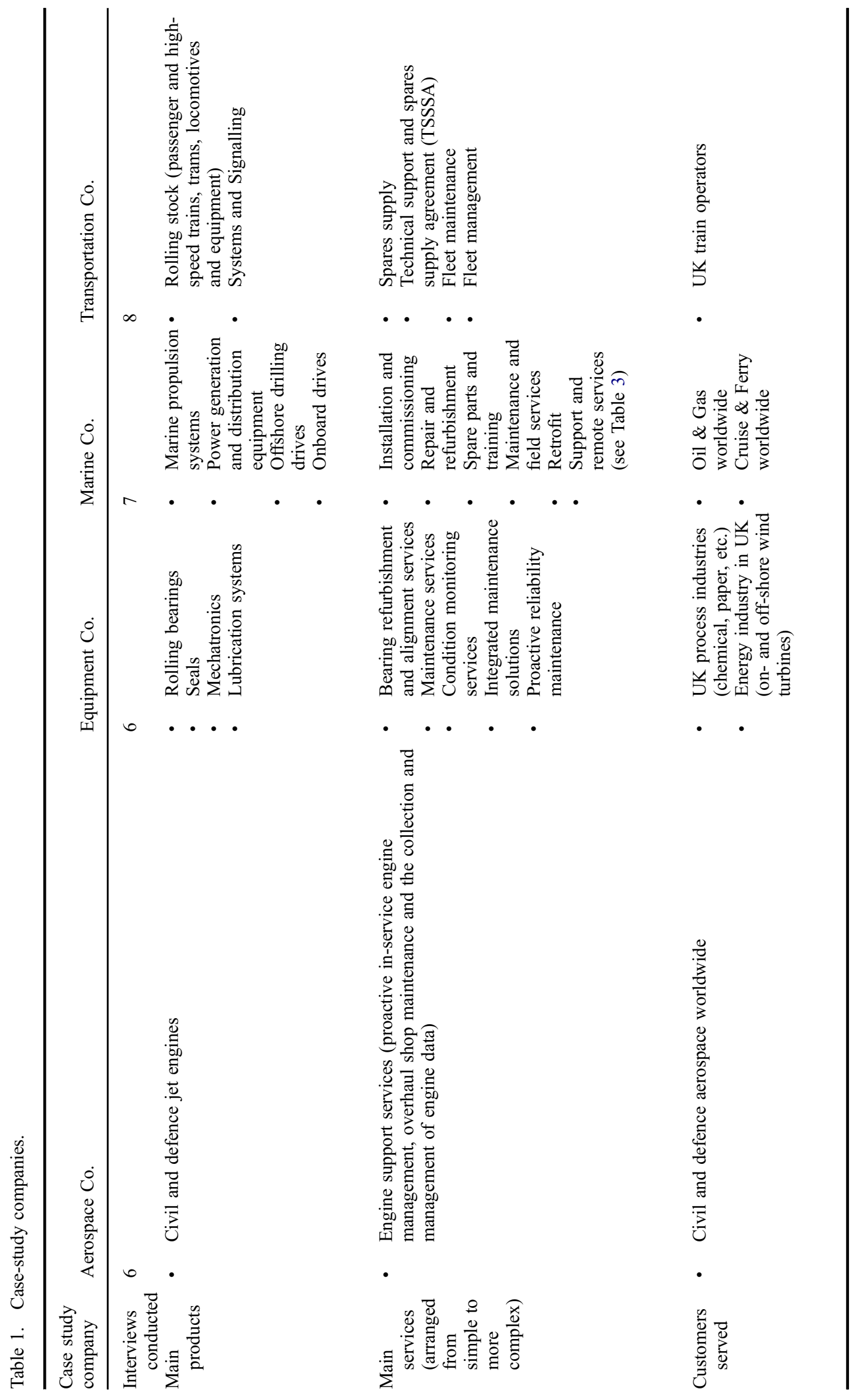


direct observations and secondary data (process maps, presentations, company reports and web sources, technical descriptions of RMT systems). Multiple sources of data were used to increase the construct validity (Yin 2003). The coding initially focused on the four categories of: challenges, nature of product, RMT functionality and other. The first three were identified in the literature and served initially as tentative constructs. Specifying a priori constructs is recommended practice when building theories from case-study research (Eisenhardt 1989). The fourth category was intended to capture any other factors not previously identified. To decide whether to include a factor we relied on the following three criteria: (1) Is the factor applicable beyond the immediate context? (2) Did multiple participants mention the factor? (3) Does the factor provide any interesting and useful conclusions? For example, the hierarchical level factor was only rarely mentioned in the interviews, but it was included because it complements other factors (RMT functionality and nature of product) thus providing more nuanced and complete explanations. To ensure detection of relevant factors within-case analysis was coded independently by two researchers. The results were then compared and discussed until an agreement was reached about factors and their interconnections.

An individual case-study report was then produced for each company and subsequently verified by them. Cross case analysis was then undertaken. This involved a search for patterns in the factors and their interconnections. We also employed the relevant literature, the role of which is recognised as essential in this stage of case-study research (Eisenhardt 1989). Theory-building from cases occurs through recursive cycling between the case data, emerging theory and extant literature (Eisenhardt and Graebner 2007). By extending our interests in this way, we were able to enrich our understanding of RMT business solutions and gather further validation for the overall findings.

\section{Factors shaping the business solutions}

In what follows, we propose six factors that have been found to characterise application of RMT in the context of servitised strategies. These are:

(1) Value proposition: what is being sold or contracted for?

(2) Nature of product: mechanical, electrical or a mix?

(3) Hierarchical level: from components to systems.

(4) RMT functionality: spectrum from simple BIT to prognostics.

(5) Data collection: type, amount and frequency of capture.

(6) Challenges and Enablers: a number of other considerations.

\section{Value proposition}

A value proposition provides the compelling reason for a customer to purchase a product or service or both. Our analysis suggests that RMT enables a broad range of value propositions, which is in agreement with the existing research that recognises different combinations of products and services. Baines et al. (2009) argue that these combinations can be positioned on a product-service continuum that ranges from products with services as an 'add-on' on one end, to services with tangible goods as an 'add-on' on the other. A similar is found in Shelton (2009) and Baines and Lightfoot (2014). All propose three very broad product and service combinations: (1) base (product sale, installation, spares or scheduled maintenance), (2) intermediate (training, customer support, preventive maintenance, overhaul, financial services, or performance enhancement services) and (3) advanced (integrated solutions, such as availability contracts).

We have also found that RMT, to varying degrees, supports a broad spectrum of product and service combinations (Table 2), from warranty to availability contracts. They reflect value propositions with ascending degrees of risk to a service provider and business propositions for customers. Risks involved in delivering data analysis are lower than those involved in delivering availability contracts. Benefits for customers follow a similar logic. We often found that companies would employ the same RMT system to support delivery of various value propositions. The difference is in the diverse set of enablers that complement the system and in challenges that have to be overcome, the two considerations presented later.

Marine Co. uses its RMT system in the delivery of remote troubleshooting service, which centres on a value proposition of on-demand connectivity to assist in remotely diagnosing a failure on a specific Marine Co. product. This can be classified as a data analysis service. The same system is also used to mitigate warranty-related risks. By using this system during the warranty period Marine Co. can see if a fault was caused by their equipment or by some other equipment on the vessel, which may save them from unnecessarily dispatching engineers to fix the fault. Transportation Co. uses the same RMT systems in the delivery of value propositions that centre on data analysis and availability contracts. Examples for the former are TSSSA and Fleet Maintenance contracts, which Transportation Co. provides to several train 
Table 2. Range of value propositions enabled by RMT.

\begin{tabular}{|c|c|c|}
\hline Value proposition & Description & Example from a case study \\
\hline Warranty & Mitigates risks in the warranty period & $\begin{array}{l}\text { - Prevention of unnecessarily dispatching } \\
\text { engineers (Marine Co.) }\end{array}$ \\
\hline Sell technology & $\begin{array}{l}\text { Sale, installation, and } \\
\text { commissioning of } \\
\text { RMT systems }\end{array}$ & $\begin{array}{l}\text { - Sale of RMT systems used in the provision } \\
\text { of condition monitoring services to customers (Equipment Co.) } \\
\text { - Sale of less sophisticated RMT systems to the main competitors } \\
\text { (Equipment Co.) }\end{array}$ \\
\hline Data collection & $\begin{array}{l}\text { Services around data collection } \\
\text { and initial } \\
\text { data processing (without data } \\
\text { analysis) }\end{array}$ & - Condition monitoring services (Equipment Co.) \\
\hline Data analysis & $\begin{array}{l}\text { Services around data analysis and } \\
\text { identification and failure } \\
\text { prediction }\end{array}$ & $\begin{array}{ll}\text { - } & \text { Troubleshooting remote service (Marine Co.) } \\
\text { - } & \text { TSSSA contracts, Fleet maintenance (Transportation Co.) } \\
\text { - } & \text { Collection and management of engine data (Aerospace Co.) } \\
& \text { Condion monitoring services (Equipment Co.) }\end{array}$ \\
\hline Availability contracts & $\begin{array}{l}\text { Taking responsibility for } \\
\text { equipment } \\
\text { and giving guarantees on its } \\
\text { availability }\end{array}$ & $\begin{array}{l}\text { Proactive in-service engine management } \\
\text { (Aerospace Co.) } \\
\text { - Fleet management, no customers at the } \\
\text { time of study (Transportation Co.) } \\
\text { - Used to be provided by Equipment Co. }\end{array}$ \\
\hline
\end{tabular}

operators in the UK. TSSSA are usually provided to those operators who have knowledge and expertise in train maintenance and have recently acquired new trains for whose maintenance they have not yet developed the necessary knowledge. Transportation Co. supports these customers by providing technical support and the knowledge necessary for first line fault finding. Fleet maintenance contracts are developed for those operators who are not interested in developing maintenance expertise but see their core business as moving passengers and providing other value-adding services (food, Wi-Fi, etc.) to them. Transportation Co. would then provide maintenance and use RMT for that purpose.

In the case of availability contracts, although Transportation Co. provides fleet management contracts which guarantee a certain level of train availability and would involve assigning trains to the operator's schedule, at the time of our study they did not have any customers. Equipment Co. used to support availability contracts but they realised that the risks involved outweigh the benefits gained. Their business rests mainly on data collection and data analysis services. In case of the former, Equipment Co. collects the data and performs the initial data cleansing and then delivers the data to customers who perform the analysis and subsequent maintenance themselves. In case of data analysis services, this work, apart from maintenance, is done entirely by Equipment Co. The same RMT systems used to provide and support these two value propositions are also sold to those customers who wish to perform maintenance themselves. Equipment Co. even sells less sophisticated versions of these systems to its main competitors.

In Aerospace Co. there is evidence for the existence of availability contracts. In delivering these contracts, the same RMT systems that support the delivery of data analysis services are used. The latter are services centred on the collection and management of engine data which is provided to customers not interested in availability contracts. These customers, similar to TSSSA of Transportation Co., usually have the maintenance expertise in-house which they supplement with data analysis services provided by Aerospace Co. In the case of availability contracts, RMT is used in providing real-time data about the state of gas turbines in the field. This data, collected from more than 3,500 engines around the world, is turned into diagnostic and prognostic information necessary to mitigate the risks of availability contracts. 


\section{Nature of product}

By this we mean whether the product is mechanical, electro-mechanical or electrical/electronic. The importance of this factor was identified in the literature (Grubic et al. 2011; Lerch and Gotsch 2015) and its significance further confirmed in the case studies. The nature of a product is an important factor as it conditions the RMT functionality, which in turn directly affects the possible value propositions that can be enabled for the product. Because of this, discussion of this factor cannot be detached from RMT functionality (see below). The key point here is that not all RMT functionalities can be supported for all types of products. Mechanical products, bearings (Table 1), are made by Equipment Co. and hence most of its RMT systems are developed to support fault detection and analysis for these. Such products continuously deteriorate with time and this change can be detected and possible implication of this potentially predicted (e.g. fault or failure). Conversely, purely electrical/electronic components, as is the case with drives or power generation and distribution products of Marine Co., do not deteriorate in a continuous, but in a discrete manner. This reduces our ability to detect change in their parameters, and consequently to predict their ultimate failure. For this reason, Marine Co. does not currently have prognostic functionality. Finally, products made by Aerospace Co. and Transportation Co. are broadly defined as electro-mechanical, i.e. consisting of a mixture of electrical/electronic and mechanical parts. Such hybrid products manifest both kinds of deterioration mechanisms, continuous for mechanical and discrete for electrical/ electronic, hence having different RMT functionalities.

\section{Hierarchical level}

Independent of their nature, products are usually built in a hierarchical manner. Starting from the lowest level, i.e. parts or components, combined together to form subsystems, and finally to the highest level of a system or product. Similar to the nature of the product factor above, the significance of hierarchical level becomes obvious only when considered together with the functionality factor. When combined the two factors reveal a challenge that derives from the mismatch between the levels at which data are collected and analysis is conducted. Namely, RMT collects system or product-level data on what we call collective variables, whereas analysis aims to find faults with the individual parts or components. The following from Aerospace Co. may explain:

I could expect an engine of a certain life to have a certain turbine gas temperature margin. If I am half way through the life I already have an idea of how much should be remaining on this engine. You can start to interrogate and question and derive expectations that something is not quite right because I have lost my entire margin at this life and that tells me that something is not right and you can then start to investigate. [RMT Operations Manager]

The temperature margin may be seen as the collective variable and its change may suggest an issue with a gas turbine. However, the identification of the root cause of this change is not straightforward as the data tell nothing about what caused the change, and where on the turbine this may be located. The case of Equipment Co. is even more revealing (see also interview excerpt from Equipment Co. in Challenges and Enablers section below). They collect vibration data (collective variable) on bearings (parts or components) and then analyse this data to understand what it means for the larger system that surrounds the bearings, e.g. a machine tool. Therefore, RMT provides companies with product level data on collective variables (e.g. turbine gas temperature or machine tool vibration), which they then need to translate into diagnostic and prognostic information about the state and health of constituent parts and components.

\section{Functionality}

This factor proposes a spectrum of different RMT functionalities (Table 3). It is directly related to the nature of product and hierarchical level factors, and together with them conditions the scope of possible value propositions. Its inclusion was inspired by the literature (Grubic et al. 2011; Porter and Heppelmann 2014; Novales, Mocker, and Simonovich 2016). To overcome the lack of agreement recognised there, we have adopted the typology by Jardine, Lin, and Banjevic (2006) that has specifically been developed to describe the nature of RMT. The typology divides RMT into four levels: monitoring, detection, diagnostic and prognostic. Through the case studies, we also identified built-in-test (BIT) which embeds self-test monitoring. To mark the inherent and essential differences, the five functionalities are further divided into two groups, with each functionality building on the preceding one.

Depending on application, BIT typically undertakes a comprehensive 'power on' test in which key functional parts or subsystems are tested to ensure integrity before the system being tested is actually started. In the event that the 'power on' test fails the following may occur: (i) a reduced functional capability may be directed that maintains critical functions only (limp mode), or: (ii) the function is transferred to an alternative system (redundancy). The ability to 
Table 3. RMT functionalities and their definition.

\begin{tabular}{|c|c|c|c|}
\hline Functionality & & Definition & Example from a case study \\
\hline \multirow[t]{2}{*}{ Monitoring } & Built-in-test & $\begin{array}{l}\text { Before the use of a product can } \\
\text { commence, } \\
\text { built-in-test aims to establish whether any } \\
\text { of its components or sub-systems is } \\
\text { functional thus preventing potential } \\
\text { damage by transferring the function onto a } \\
\text { redundant component or subsystem. } \\
\text { Compared to other levels, built-in-test can } \\
\text { be considered as the least complex of all }\end{array}$ & $\begin{array}{l}\text { Variable frequency converters and } \\
\text { PLCs of electric propulsion systems, } \\
\text { drives, and switchboards (Marine } \\
\text { Co.) } \\
\text { Electric traction systems, power } \\
\text { supply, batteries (Transportation Co.) }\end{array}$ \\
\hline & Monitoring & $\begin{array}{l}\text { A functionality of collecting data about } \\
\text { a product but with no subsequent } \\
\text { resultant action }\end{array}$ & $\begin{array}{l}\text { Variable frequency converters and } \\
\text { PLCs of electric propulsion systems, } \\
\text { drives, and switchboards (Marine } \\
\text { Co.) } \\
\text { In addition to above mentioned } \\
\text { subsystems, monitoring is deployed } \\
\text { on the following electro-mechanical } \\
\text { subsystems: engines, gearboxes, fluid } \\
\text { levels, HVAC, doors, toilets } \\
\text { (Transportation Co.) } \\
\text { Rolling bearings (Equipment Co.) } \\
\text { Turbine gas temperature, turbine } \\
\text { cooling air temperature, fan delivery } \\
\text { pressure (Aerospace Co.) }\end{array}$ \\
\hline \multirow[t]{3}{*}{ Processing/Analysis } & Detection & $\begin{array}{l}\text { Builds on monitoring functionality } \\
\text { by processing the data collected and } \\
\text { providing information about the fault } \\
\text { or failure occurrence }\end{array}$ & - Same as in Monitoring \\
\hline & Diagnostic & $\begin{array}{l}\text { Centred on determining a type, location, } \\
\text { and a root cause of a fault or failure in } \\
\text { order to determine the ability of a product } \\
\text { to } \\
\text { perform its function }\end{array}$ & - Same as in Monitoring \\
\hline & Prognostic & $\begin{array}{l}\text { Defined as prediction and determination of } \\
\text { the remaining useful life of a product }\end{array}$ & $\begin{array}{l}\text { Same as in Monitoring expect for } \\
\text { Marine Co. }\end{array}$ \\
\hline
\end{tabular}

seamlessly transfer function to an alternative system provides for service continuity. Additional benefits of BIT include allowing a failed unit to be replaced quickly and easily, which minimises downtime, and allowing for a reduced field technician skill set. However, it has significant cost, weight and space implications associated with the redundancy.

Application of BIT functionality is found in Marine Co. and to a certain extent in Transportation Co. Most Marine Co. RMT-enabled products are of electronic nature that has tests aiming to establish whether any of their components are non-functional before operation. This allows preventative action to be taken by transferring the function onto redundant components and subsystems, thus preventing potential damage. Most electrical subsystems on a train, e.g. electric traction system or batteries, are equipped with BIT. However, BIT cannot be deployed on products which are of mechanical nature explaining why Aerospace Co. and Equipment Co. are not mapped onto this functionality. The electrical/electronic products may be designed with redundancy and an ability to collect data 'on-line', while mechanical products are predominantly 'off-line' systems. BIT comes in discrete and continuous versions differing in the manner they collect data and test the status of products. Marine Co. products use both categories as some of their products start collecting data after an anomaly or fault occurs while others may do this on a limited but continuous basis.

The monitoring functionality for electronic/electrical products may also contain BIT, which explains the mapping of Marine Co. in this category. The products of other three companies are electro-mechanical (Aerospace Co. and 
Transportation Co.) and mechanical (Equipment Co.) in nature. Thus, apart from collecting data on electronic/electrical parameters, e.g. currents or voltages in batteries, Transportation Co. also monitors other electrical (e.g. doors), and mechanical (e.g. gearboxes), subsystems. Aerospace Co. collects data about mechanical parameters, e.g. turbine gas temperature, turbine cooling air temperature and fan delivery pressure. A final example is the monitoring of vibration in rolling bearings, as in the case of Equipment Co., which provides an essential input to the remaining three functionalities of detection, diagnostic and prognostic.

Detection is present in all four case-study companies and it aims to provide information about the fault or failure occurrence by analysing the data collected through monitoring. The difference between the functionalities of builtin-test, monitoring, and detection with the diagnostic and prognostic functionalities is that the latter functionalities are not done in completely automated fashion but mediated by human actors. The first three functionalities can be completely automated and executed without human involvement or intervention, which cannot be said for diagnostic and prognostic. In the case of diagnostic functionality, determining a type, location and a root cause of a fault or failure is done in a semi-automatic manner involving two steps, which somewhat overlap. The first includes data automatically collected via the monitoring functionality and analysed for the presence of any abnormality by means of detection functionality. Detection is triggered automatically once an abnormality in data is detected; meaning that detection is only possible if the abnormality signature has already been encountered and recorded. That is, no records, no detection; no detection, no faults. This is similar to Jonsson, Westegren, and Holmström (2008) who recognised that RMT can only detect what the technology is designed to detect and there will always be faults that are beyond its reach. The second step involves idiosyncratic human experience augmented by knowledge from a database holding a rich source of past cases. The two sources produce diagnostic and prognostic information. An example for this can be seen from the following Marine Co. interview extract:

There could be many underlying reasons in fault codes, especially in the drives. If the drive trips there will be at least 6 fault codes, it will never show only one. [RMT Service Support Engineer in Norway]

Marine Co. does not currently have prognostic functionality. This is not because their technical capabilities are lagging behind those of other three case-study companies, but because such functionality is not possible for pure electronic/ electrical products. To demonstrate this, we only need to think of light bulbs and our inability to predict their remaining useful life.

\section{Data collection}

RMT applications differ according to type, amount and frequency of the data collected. Type of data is defined as belonging to any of the three broad groups of: status, structure and environment. These types are of various importance and support service delivery in their own ways. All four companies collect data on the status of their products, for example, performance or product usage. This data is crucial for determining the current and predicted condition and health of the product and is evidenced in the data companies collect on, for example, vibration, pressure and currents (Table 3).

Data about structure aims to determine the latest version or build of the product. At the moment only Aerospace Co. and Transportation Co. collect such data. This data is of particular importance for delivery of availability contracts, which may explain why only these two companies gather it. By having an insight into the product's configuration or bill of materials, a company can determine what version the product belongs to and whether the latest engineering modifications, aiming to progress availability, have been implemented. Another practical benefit of having the configuration data is in knowing the service history of each component that makes a product. The potential challenge here is data integration which has already been recognised in the literature (Brax and Jonsson 2009; Kuschel 2009; Mahlamäki et al. 2016). Namely, status and structure data are collected by and reside in different systems, developed to support different purposes.

The final type should be understood as data about products and how they 'interact' with a wider environment, not just environment in a narrow sense of the word. No evidence was found to conclude that companies collect such data. Aerospace Co, Marine Co., and Transportation Co. collect data on certain aspects of the product-environment interaction (e.g. speed and location). But environment data should be extended to include data about the wider contextual setting that surrounds the product. The RMT systems used by the case studies allow collection of such data to a very limited extent. This data provides a crucial piece of the puzzle when conducting diagnostic and prognostic analyses, both heavily dependent on human involvement. As the following interview excerpt shows, acquisition of environment data is mainly done by human senses rather than technology. 
When I go out on the customer site I am starting afresh but within a few months of doing it I am in stage where I fully understand how that machine works and any little idiosyncrasies with it and how the customer uses that machine or whatever; it is like a 'gut feeling' and that enables you when you measure it to relate to it and when you looking at it analysing the data you can relate to the data and understand why the data is the way it is because you understand the machine itself. When you are doing a remote analysis and there is more of this coming along all the time it is very difficult actually to get a feel for the machine when you are just looking at the vibration signals that have come from it. Unless you know that machine it makes the job quite a lot harder. [Predictive maintenance specialist, Equipment Co.]

Closely related to the type are the amount and frequency of data collected. The data collected in the case studies did not give us enough evidence to make definite conclusions about this matter. However, it is observed that companies work with very limited data. This makes their analysis a challenge yet it also demonstrates the abilities of their analysts and RMT systems to extract the relevant information. For example, Aerospace Co. collects six reports per flight amounting to around 10,000 reports per day, but each report contains only around $3 \mathrm{kB}$ of data.

Finally, frequency of data collected can be divided into scheduled (discrete) and continuous data collection (Jennions 2013). All case companies work in the scheduled 'mode', which involves collecting data in certain predetermined time frames. A good example is a contract of Equipment Co. with a customer from the shipping industry. Only once a month they are allowed to take a 5-min sample of data from each of a few measurement points. From this they are expected to provide reliable diagnostic and prognostic analyses. Explanation for the absence of continuous data collection may be found in a combination of technical and economic reasons which render continuous data collection either technically unfeasible or economically unviable.

\section{Challenges and enablers}

Delivery of a value proposition characterised by the nature of product, its hierarchical position, RMT functionality, and type, amount and frequency of data collected, conditions the nature and extent of challenges that will have to be overcome. A number of challenges are recognised in the literature and further confirmed and enriched in the case studies. The case studies also identified a number of enablers that have to be in place to successfully deliver and support the value proposition. This is because a technology will not deliver its potential unless the wider system in which it resides is considered. Challenges and enablers, identified in the case studies and literature, are the last two factors examined here. Figure 2 integrates these findings into a map. The map suggests that there exists a very complex relationship between enablers and challenges. This complexity is further amplified once the preceding five factors are considered. Next we describe some examples on how challenges and enablers are affected by the other five factors.

As both Marine Co. and Equipment Co. discovered, challenges exist even for 'simple' warranty or sale of RMT system value propositions. In the case of Marine Co. and their warranty contracts, they discovered the lack of support from customers. Customers are not always prepared or interested in providing additional data around a problem or failure. This data belongs to the environment type and is essential in helping a service engineer resolve a failure. The customer's attitude changes once the warranty period expires and the contract changes to a data analysis value proposition. In the case of Equipment Co. and the sale of their RMT systems, the challenge is an internal one and involves misalignment of strategies, and consequently incentives, between the product and service side of the company. This is manifested in the situation where the sales team having a limited understanding of RMT sells an RMT system that may not be the optimal solution for the customer. The system inadequacy becomes evident when the customer invites Equipment Co. to deliver data collection or data analysis services or even decides to do those on their own.

Challenges surrounding delivery of the data collection value proposition may be considered as mainly technical in nature. The main aim is to collect the necessary data and do the initial data processing without any data analysis. The greatest challenge here is to make sure that the data acquisition and transmission can be achieved. This can be done by checking and calibrating sensors and other infrastructure on a regular basis. Equipment Co. checks and calibrates sensors on a routine basis to overcome some of the innate limitations of RMT. This is because RMT itself could be a potential source of error (Jonsson, Westegren, and Holmström 2008).

The data analysis value proposition includes not only data collection and processing but analysis and identification of faults, even failure prediction. Key enablers here are the skills, experiences and knowledge of the individual analysts necessary to 'decipher' the data collected. The capacity to analyse and interpret RMT data is identified as one of the key strategic capabilities for manufacturing companies shifting towards services (Ulaga and Reinartz 2011). The importance of this is best demonstrated in the following statement by the General Manager in Equipment Co.

The more skilled the analyser or the service provider if you like it, he has that background to look at a machine and understand how the machine is functioning. That is what we are looking for when we are employing these guys and it is not just their 


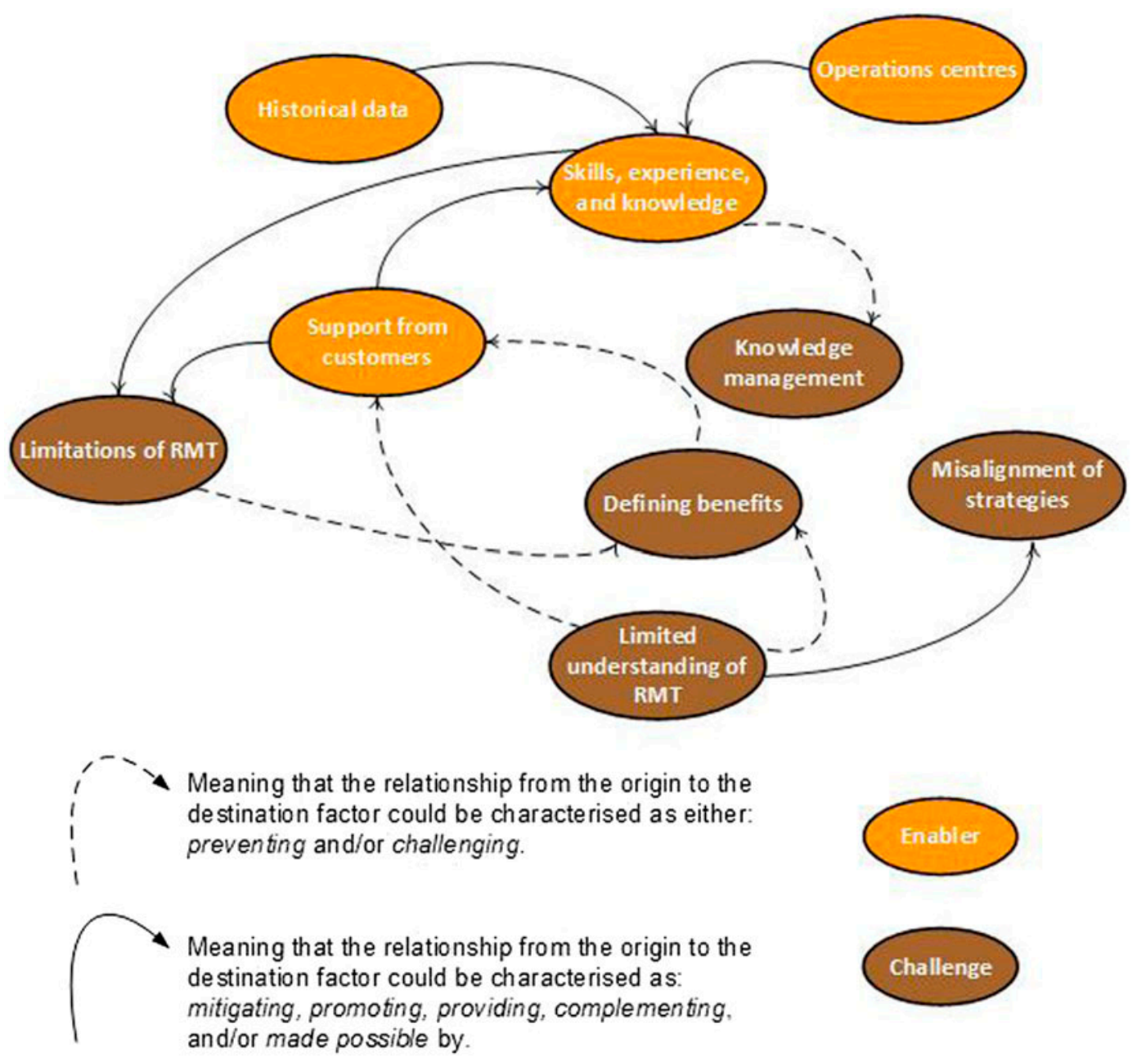

Figure 2. Challenges and enablers of RMT - examples from the case studies and literature.

capability in using different types of analysers or software because that is all trainable; you can train guys to do that. But it is very difficult to train them to understand when they look at the gear box for them to be able to visualise what is going on within that gear box which is important. Because when they are analysing the vibration signatures they need to be able to understand how that relates to the asset they are monitoring it from.

The key challenge here is limited understanding about the true capabilities of RMT by the customer, which may prevent the service provider from successfully delivering their value proposition. Some Equipment Co. customers are not aware of the limitations of RMT, or more precisely, the reduced picture of reality it provides. This refers to a gap between the digital world of the data collected and the real physical world of the product being monitored (Jonsson, Holmström, and Lyytinen 2009). An analyst can be working with data that is giving her a much reduced picture of reality, while the customer is expecting a reliable analysis. Some Equipment Co. customers are not aware of the role they play in providing necessary data, mainly about the wider context, to enrich this picture. Their input is crucial in two ways. First is by providing the necessary contextual data. Second is by providing feedback on the analyses. The latter helps to validate and improve the precision of diagnostic and prognostic analyses. This is in agreement with Grubic (2014), Wuenderlich et al. (2015) and Lenka, Parida, and Wincent (2017) who recognised co-creating nature of RMT-enabled services.

In terms of the number, extent, diversity and nature of the challenges and enablers involved, availability contracts are by far the most complex value proposition provided. By helping service providers to determine current and predicted health of the product, RMT can mitigate the risks of product non-availability. However, RMT still heavily depends on people's skill, experience and knowledge, and support from customers. In addition, operations centres and historical data are also recognised as essential enablers in the delivery of availability contracts. Aerospace Co. has two operations 
centres in the UK and one in Germany. They provide a holistic view into problems and facilitate deployment of solutions across the whole installed base. Operations centres promote learning and knowledge sharing necessary to mitigate the risks of availability contracts. They help in creating insights into required engineering modifications that will increase the product availability. Operations centres are equipped with a rich database of past cases. This historical data is essential in supporting the skills of individual analysts by means of recommendations and suggestions built from past cases. Equipment Co. has collected over 10 years' worth of data that facilitate and enable comparison with past cases thus supporting analysts in making better diagnostic and prognostic decisions.

Many of the challenges can be removed with strong top-level support. Yet, misalignment of strategies between the services and design still exist. In Aerospace Co. this is seen in the resistance of the design to add new sensors required in the service delivery. In the eyes of the former sensors are usually the first things to be deleted when confronted with problems with weight or cost. This shows a lack of understanding for the importance of RMT for service.

\section{Discussion}

This study has attempted to address the following question: What factors characterise the organisational application of RMT in the context of servitised strategies? In relation to this it makes two contributions. The first comes in the form of six factors found to characterise this application. They reveal the complexities between RMT and servitisation implying the limited scope for the development of prescriptive approaches. The second contribution is that it questions the feasibility of some servitised strategies and the role of RMT therein. More precisely, it questions our understanding of outcome-based contracting, which has recently gained a lot of interest. We will next elaborate the two contributions.

\section{Factors characterising application of RMT for servitised strategies}

Through a research process that combines literature and four in-depth case studies, we propose that the relationship between RMT and servitised strategies can be characterised with a framework consisting of at least six factors. The framework can be seen as an attempt to consolidate the existing evidence thus providing a more holistic account on this largely fragmented and little understood phenomenon. The validity of the framework is partially corroborated by similar findings by Porter and Heppelmann (2014). They identified 10 strategic choices faced by manufacturing companies considering RMT applications. The choices covered the areas of: (1) RMT functionalities (type, how much to embed in the product, develop in-house or outsource), (2) data (what data to capture and how to manage its ownership) and (3) value (business model related considerations). The similarities with our framework are evident. Areas where our framework makes explicit advances are in identifying and providing a detailed account of key factors and in exploring their strategic implications, both recognised as missing in the current literature (Novales, Mocker, and Simonovich 2016).

The framework suggests that when applying RMT to support servitised strategies, companies should consider:

(1) What product and service combination value proposition is enabled by RMT?

(2) What is the nature of the product?

(3) What hierarchical level in the customer's business does the product hold?

(4) What RMT functionality is required to support the value proposition?

(5) What types and amount of data, and how often this data have to be collected to support delivery of the value proposition?

Answers to these questions either explicitly or implicitly condition the number, nature and extent of challenges that have to be overcome, and enablers that have to be in place to support the RMT-enabled business solutions. Framed in this way one may conclude that identification of possible value proposition, which takes into account the nature of product, functionality, hierarchical level and data collection, should be the first step in the analysis. This approach may well work in certain contexts, however, the situation is far more complex than this linear approach suggests. For that reason, a more holistic and ecological approach is advocated, as the one illustrated in Figure 3 and elaborated next.

Figure 3 suggests that there may be relationships which are not entirely linear but circular. These relationships are constituted by dependencies which at the same time are affecting the outcome and the process of defining the scope of possible value propositions. For example, the selection of functionality may be affected by the existence of necessary skills, experience and knowledge which was identified as a key enabler. But acquiring such knowledge is not a simple task as evidenced in the knowledge management challenge. This knowledge cannot simply be purchased off-the-shelf as it is very context specific and its development may take many decades. If this knowledge is not present in-house, then possible functionality will be constrained, further constraining the scope of possible value propositions. Another example 


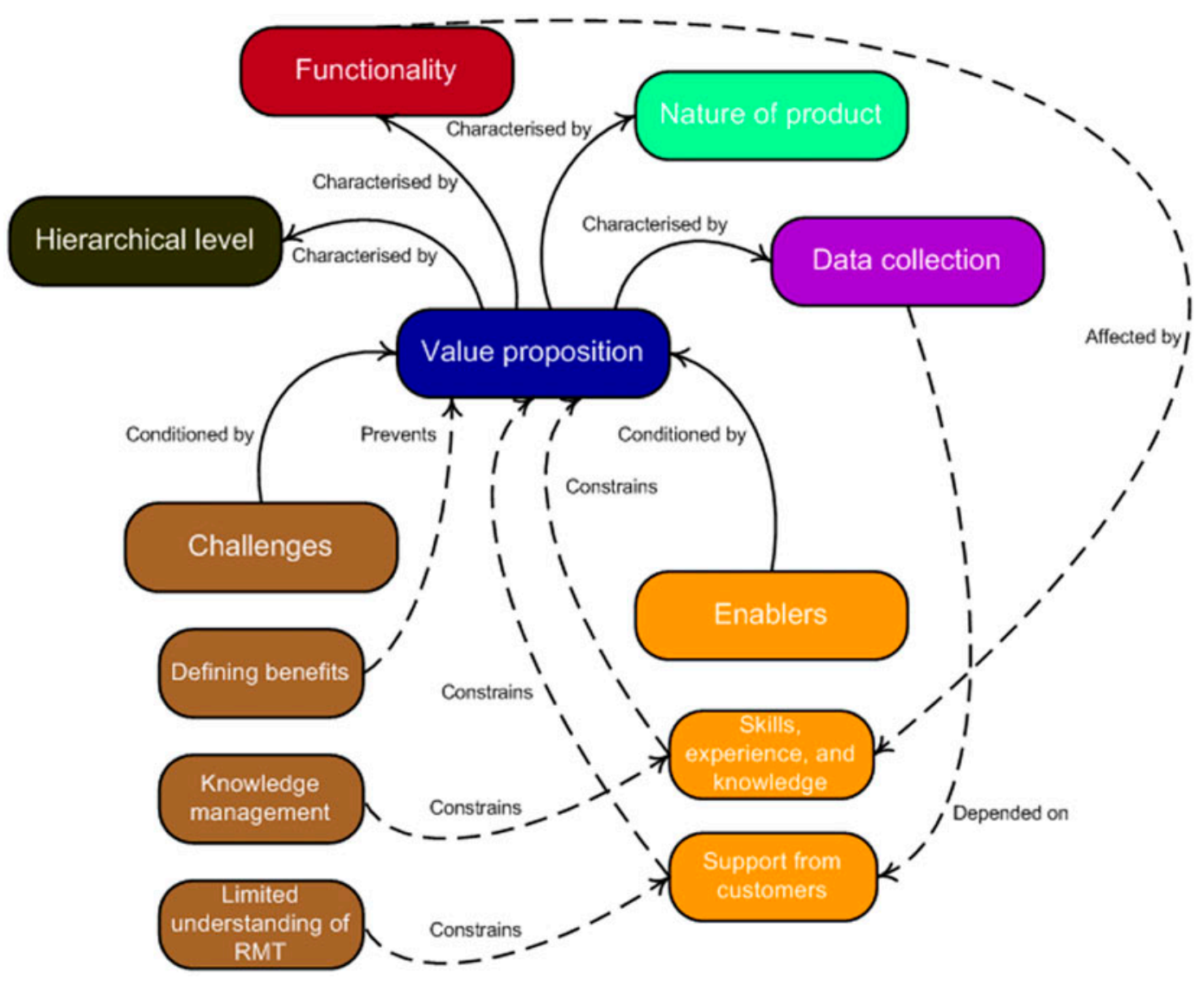

Figure 3. Complex nature of RMT and servitised strategies - examples.

concerns the relationship between value proposition, functionality, data collection and support from customer enabler. As explained before, environment data type is very important for value propositions depending on diagnostic and prognostic functionalities. Acquisition of this data is likely to depend on willingness of customers to provide support for the collection of this data type which is highly complementary to product status data collected by RMT. If it seems that such support may be problematic, for example, due to limited understanding of RMT, then scope of possible value propositions will be greatly constrained.

The key message is: there is a very complex, multi-levelled, multifaceted and circular relationship between RMT and servitised strategies. RMT-enabled service ought to be seen as being of a macro-level character that emerges from the multiple-factor interactions involved. This resonates with Chae (2014) who proposed a novel perspective on IT-enabled services, perspective that builds on complexity theory. The perspective understands IT-enabled services as structures emerging from the interaction of a diverse set (tangible and intangible) of elements. Adopting this perspective has clear implications for the management of RMT. Mainly due to the interwoven and looped nature of the multiplefactor interactions (see Figures 2 and 3), there may be a limited scope for creating prescriptive approaches for managing RMT in the context of servitised strategies. Such approaches would only mask and greatly reduce the complexity existing between the factors involved. This finding supports Novales, Mocker, and Simonovich (2016), who argued that a decision on which conceptual elements to incorporate is far from simple and clearly of strategic relevance. In that sense, the intention of the framework is not to reduce the complexity involved to a number of step-by-step prescriptions. On the contrary, it attempts to embrace this complexity by providing the lens necessary for its exploration; this is illustrated next.

\section{RMT functionality for outcome-based contracting (OBC)}

This section explores RMT functionality necessary to deliver OBC. In such contracting, which is similar to performance-based contracting (Selviaridis and Wynstra 2015), the customer pays only when the company delivers outcomes 
(Ng, Maull, and Nudurupati 2009; Ng and Nudurupati 2010; Ng, Ding, and Yip 2013). This is similar to advanced services, which Baines and Lightfoot (2014) define as outcomes focused on capability delivered through performance of the product. If the famous example by Levitt (1972) is considered, who said that 'people don't want to buy a quarterinch drill; they want a quarter-inch hole', then $\mathrm{OBC}$ would mean the customer paying only for hole in the wall. In what follows we argue that delivery of $\mathrm{OBC}$, at least from the RMT functionality perspective, is problematic, even unfeasible. That does not mean that some companies are not providing OBC. They may well be doing this but the explanation could be found in other factors, which are not strictly of technological nature.

The case studies provide no evidence to support the conclusion that these companies are offering OBCs. Even provision of availability contracts is very limited thus throwing doubts about their prevalence in business. In essence, OBCs subsume availability as well as performance or capability guarantees. Providing an availability guarantee only guarantees that the equipment will be available for use, not that it will be capable of delivering the expected service. Taking the case of electric drill, an availability contract would make it available for use for an agreed percentage of time, say $95 \%$. The contract would not guarantee that the drill had enough power to drill a hole of a given size, to a given quality, in an appropriate time. So the equipment may be available but not $100 \%$ capable of delivering the service. From the perspective of RMT, selling the use of a drill with an availability guarantee is very different to selling and guaranteeing its performance.

This may sound surprising considering the level of interest in OBC among academics and industry commentators alike. However, this may be due to confusing availability contracting for OBC. For example, Baines and Lightfoot (2014) say that advanced services are analogous to capability, availability or performance contracts. We claim that availability contracting and $\mathrm{OBC}$ are complementary but very different. To examine the difference making an analogy between OBC and Overall Equipment Effectiveness (OEE), from Total Productive Maintenance (TPM), may prove helpful. OEE is calculated by multiplying three metrics that characterise the overall equipment effectiveness: availability, performance and quality. Taking the example of drill again, availability represents the percentage of scheduled time the drill is available to operate, performance represents the speed at which the drill runs as a percentage of its designed speed and quality represents the 'good' holes drilled as a percentage of the total holes drilled. Equating OBC with OEE would mean the former is about delivering the product of all three metrics not only one of them, i.e. availability. In that sense guarantees for performance and quality would also be required. However, the RMT functionality necessary to mitigate the risks involved is not at the level to support this task. This is inconsistent with Porter and Heppelmann (2014) who claim that one of the four functionalities identified, optimisation, supports optimisation of a product's performance.

At the moment RMT only supports diagnostic and prognostic functionalities, and even these to a limited extent. For the purpose of supporting availability contracts, which subsume responsibility only for the availability metric of the OEE expression, the diagnostic and prognostic functionalities of RMT only provide part of the analysis. The rest comes from: (1) skills, experience and knowledge of individual analysts, (2) historical data, (3) operations centres and (4) support from customers. This may explain the limited number of cases in which availability contracting is offered (only Aerospace Co.) and reservations from those who tried it (Equipment Co.). When this is extrapolated to the domains of performance and quality, the remaining two metrics in the $\mathrm{OEE} / \mathrm{OBC}$ expression, the situation is far more challenging.

The RMT functionality required here is more than prognostic functionality since the latter aims to determine the remaining useful life of a product and not to foresee how its effectiveness will change. Namely, it may be possible to determine, with some certainty, that a particular part in the drill is deteriorating and it may fail in X time units. But diagnostic and prognostic science is still not capable to tell by how much the drill's capability or performance will change due to this (see Jardine, Lin, and Banjevic 2006). The RMT functionality that enables such analysis would need to provide an integrated view on how the product's availability, performance and quality change through time. Without this functionality, the risks involved in the delivery of an $\mathrm{OBC}$ would far exceed those that surround availability contracts. This may explain nonexistence of OBCs in the case studies.

\section{Conclusions}

This paper deals with the role and support of RMT in servitised strategies, an area of limited understanding. We advance this understanding by proposing a framework that characterises the application of RMT in the context of servitised strategies. The framework consists of six factors: (1) value proposition enabled by RMT, (2) nature of product, (3) its hierarchical level in the customer's business, (4) RMT functionality necessary to support delivery of value proposition, (5) type, amount and frequency of data collected by RMT and (6) other considerations that either enable or constrain application of RMT. A very complex relationship seems to exist between RMT and servitised strategies and the framework ought to be seen not as an attempt to reduce this complexity, but as an aid for its exploration. Our understanding in this respect is still in a nascent stage, but several avenues can be proposed that may inspire and guide further 
theoretical development in this area. For example, how relevant are the factors proposed here to other applications and industries? What other factors may be affecting the organisational application of RMT? We have barely begun to examine the complex relationship between RMT functionality, the nature of product and the hierarchical level factor; more research is needed to explore this relationship. The same applies to the relationship between RMT and various servitised value propositions (e.g. availability, capability or performance contracting).

The research also has several implications for practice. The proposed factors are very much interrelated and interdependent and a decision about one factor often has implications for others. This may be used in practice, for example, to analyse an existing RMT business solution or as a diagnostic tool for assessing a company's capability to use RMT. Furthermore, the factors may even provide a means to explore and navigate the strategic space. The final implication is related to outcome-based contracting (OBC). Delivery of such value propositions, at least from the RMT perspective, looks very problematic. Prognostic and diagnostic functionalities are not yet capable of delivering the analysis necessary to support $\mathrm{OBC}$. Without these functionalities, the risks of $\mathrm{OBC}$ may simply be too great for some companies.

\section{Disclosure statement}

No potential conflict of interest was reported by the authors.

\section{References}

Allmendinger, G., and R. Lombreglia. 2005. "Four Strategies for the Age of Smart Services." Harvard Business Review 83 (10): 131-145.

Baines, T., and H. Lightfoot. 2014. "Servitization of the Manufacturing Firm: Exploring the Operations Practices and Technologies that Deliver Advanced Services." International Journal of Operations \& Production Management 34 (1): 2-35.

Baines, T., H. Lightfoot, O. Benedettini, and J. M. Kay. 2009. "The Servitization of Manufacturing: A Review of Literature and Reflection on Future Challenges.” Journal of Manufacturing Technology Management 20 (5): 547-567.

Brax, S. S., and K. Jonsson. 2009. "Developing Integrated Solution Offerings for Remote Diagnostics." International Journal of Operations \& Production Management 29 (5): 539-560.

Chae, B. K. 2014. "A Complexity Theory Approach to IT-enabled Services (IESs) and Service Innovation: Business Analytics as an Illustration of IES." Decision Support Systems 57: 1-10.

Davies, A. 2004. "Moving Base into High-value Integrated Solutions: A Value Stream Approach." Industrial and Corporate Change 13 (5): 727-756.

Eisenhardt, K. M. 1989. "Building Theories from Case Study Research.” Academy of Management Review 14 (4): $532-550$.

Eisenhardt, K. M., and M. E. Graebner. 2007. "Theory Building from Cases: Opportunities and Challenges." Academy of Management Journal 50 (1): 25-32.

Ellram, L. 1996. "The Use of the Case Study Method in the Logistics Research." Journal of Business Logistics 17 (2): $93-138$.

Grubic, T. 2014. "Servitization and Remote Monitoring Technology." Journal of Manufacturing Technology Management 25 (1): $100-124$.

Grubic, T., L. Redding, T. Baines, and D. Julien. 2011. "The Adoption and Use of Diagnostic and Prognostic Technology within UK Based Manufacturers." Proceedings of the Institution of Mechanical Engineers, Part B, Journal of Engineering Manufacture 225 (8): 1457-1470.

Heng, A., S. Zhang, A. C. C. Tan, and J. Mathew. 2009. "Rotating Machinery Prognostics: State of the Art, Challenges and Opportunities." Mechanical Systems and Signal Processing 23 (3): 724-739.

Isermann, R., and P. Ballé. 1997. "Trends in the Application of Model-based Fault Detection and Diagnosis of Technical Processes." Control Engineering Practice 5 (5): 709-719.

Jardine, A. K. S., D. Lin, and D. Banjevic. 2006. "A Review on Machinery Diagnostics and Prognostics Implementing Conditionbased Maintenance." Mechanical Systems and Signal Processing 20 (7): 1483-1510.

Jennions, I. K., ed. 2011. Integrated Vehicle Health Management - Perspectives on an Emerging Field. Warrendale, PA: SAE International. ISBN 978-0-7680-6432-2.

Jennions, I. K., ed. 2013. Integrated Vehicle Health Management - The Technology, Chap. 7, Data Management, 115-136. Warrendale, PA: SAE International. ISBN 978-0-7680-7952-4.

Jonsson, K., U. H. Westegren, and J. Holmström. 2008. "Technologies for Value Creation: An Exploration of Remote Diagnostic Systems in the Manufacturing Industry.” Information Systems Journal 18 (3): 227-245.

Jonsson, K., J. Holmström, and K. Lyytinen. 2009. "Turn to the Material: Remote Diagnostics Systems and New Forms of Boundaryspanning." Information and Organization 19 (4): 233-252.

Kothamasu, R., S. H. Huang, and W. H. VerDuin. 2006. "System Health Monitoring and Prognostics - A Review of Current Paradigms and Practices." The International Journal of Advanced Manufacturing Technology 28 (9-10): 1012-1024.

Kowalkowski, C., D. Kindström, and H. Gebauer. 2013. "ICT as a Catalyst for Service Business Orientation." Journal of Business \& Industrial Marketing 28 (6): 506-513. 
Kuschel, J. 2009. "Vehicle Services.” Doctoral diss., Department of Applied Information Technology, University of Gothenburg, ISSN 1652-490, ISBN 978-91-628-7870-2.

Küssel, R., V. Liestmann, M. Spiess, and V. Stich. 2000. “TeleService a Customer-oriented and Efficient Service?" Journal of Materials Processing Technology 107 (1-3): 363-371.

Lenka, S., V. Parida, and J. Wincent. 2017. "Digitalization Capabilities as Enablers of Value Co-creation in Servitizing Firms." Psychology \& Marketing 34 (1): 92-100.

Leonhardt, S., and M. Ayoubi. 1997. "Methods of Fault Diagnosis." Control Engineering Practice 5 (5): 683-692.

Lerch, C., and M. Gotsch. 2015. "Digitalized Product-service Systems in Manufacturing Firms: A Case Study Analysis." ResearchTechnology Management 58 (5): 45-52.

Levitt, T. 1972. "Production Line Approach to Service." Harvard Business Review 50 (4): 41-52.

Lightfoot, H., T. Baines, and P. Smart. 2013. "The Servitization of Manufacturing." International Journal of Operations \& Production Management 33 (11/12): 1408-1434.

Luoto, S., S. A. Brax, and M. Kohtamäki. 2017. "Critical Meta-analysis of Servitization Research: Constructing a Model-narrative to Reveal Paradigmatic Assumptions.” Industrial Marketing Management 60 (1): 89-100.

Mahlamäki, K., J. Borgman, J. Rämänen, J. Tuovinen, M. Finne, O. Perminova-Harikoski, J. Tiihonen, and M. Öhman. 2016. "Elements of Installed Base Information Value." ICE/IEEE International Technology Management Conference, Trondheim, Norway, June 13-15.

Mathieu, V. 2001. "Product Services: From a Service Supporting the Product to a Service Supporting the Client." Journal of Business \& Industrial Marketing 16 (1): 39-61.

Meredith, J. 1998. "Building Operations Management Theory through Case and Field Research." Journal of Operations Management 16 (4): $441-454$.

Ng, I. C. L., and S. S. Nudurupati. 2010. "Outcome-based Service Contracts in the Defence Industry - Mitigating the Challenges." Journal of Service Management 21 (5): 656-674.

Ng, I. C. L., R. Maull, and S. S. Nudurupati. 2009. "Outcome-based Contracts as a Driver for Systems Thinking and Servicedominant Logic in Service Science: Evidence from the Defence Industry.” European Management Journal 27 (6): $377-387$.

Ng, I. C., D. X. Ding, and N. Yip. 2013. "Outcome-based Contracts as New Business Model: The Role of Partnership and Value-driven Relational Assets." Industrial Marketing Management 42 (5): 730-743.

Novales, A., M. Mocker, and D. Simonovich. 2016. "IT-enriched "Digitized" Products: Building Blocks and Challenges." AMICS, San Diego, August 11-14.

Oliva, R., and R. Kallenberg. 2003. "Managing the Transition from Products to Services." International Journal of Service Industry Management 14 (2): 160-172.

Ostrom, A. L., A. Parasuraman, D. E. Bowen, L. Patrício, and C. A. Voss. 2015. "Service Research Priorities in a Rapidly Changing Context." Journal of Service Research 18 (2): 127-159.

Paluch, S. 2014. "Customer Expectations of Remote Maintenance Services in the Medical Equipment Industry." Journal of Service Management 25 (5): 639-653.

Porter, M. E., and J. E. Heppelmann. 2014. "How Smart, Connected Products are Transforming Competition." Harvard Business Review 92 (11): 64-88.

Raddats, C., J. Burton, and R. Ashman. 2015. "Resource Configurations for Services Success in Manufacturing Companies." Journal of Service Management 26 (1): 97-116.

Schumann, J. H., N. V. Wünderlich, and F. Wangenheim. 2012. "Technology Mediation in Service Delivery: A New Typology and an Agenda for Managers and Academics." Technovation 32 (2): 133-143.

Selviaridis, K., and F. Wynstra. 2015. "Performance-based Contracting: A Literature Review and Future Research Directions." International Journal of Production Research 53 (12): 3505-3540.

Shelton, R. 2009. "Integrating Product and Service Innovation.” Research-Technology Management 52 (3): 38-44.

Smith, D. J. 2013. "Power-by-the-hour: The Role of Technology in Reshaping Business Strategy at Rolls-Royce." Technology Analysis \& Strategic Management 25 (8): 987-1007.

Story, V. M., C. Raddats, J. Burton, J. Zolkiewski, and T. Baines. 2017. "Capabilities for Advanced Services: A Multi-actor Perspective." Industrial Marketing Management 60: 54-68.

Ulaga, W., and W. J. Reinartz. 2011. "Hybrid Offerings: How Manufacturing Firms Combine Goods and Services Successfully." Journal of Marketing 75 (6): 5-23.

Vargo, S. L., and R. F. Lusch. 2004. "Evolving to a New Dominant Logic for Marketing.” Journal of Marketing 68 (1): 1-17.

Waters, N. 2009. "Engine Health Management." Ingenia, June (39), 37-42.

Wuenderlich, N. V., K. Heinonen, A. L. Ostrom, L. Patricio, R. Sousa, C. Voss, and J. G. A. M. Lemmink. 2015. “'Futurizing' Smart Service: Implications for Service Researchers and Managers.” Journal of Services Marketing 29 (6/7): $442-447$.

Yin, R. K. 2003. Case Study Research - Design and Methods. 3rd ed. Thousand Oaks, CA: Sage. 
2017-05-25

Remote monitoring technology and pÿservitised strategies factors characterising the organisational application

Grubic, Tonci

Taylor and Francis

pÿGrubic T, Jennions I. Remote monitoring technology and servitised strategies factors characterising the organisational application. International Journal of Production Research, Volume 56, Issue 6, 2018, pp. 2133-2149

https://doi.org/10.1080/00207543.2017.1332791

Downloaded from Cranfield Library Services E-Repository 